\title{
Opioid Doctor Shopping: A Rare Phenomenon Among Patients with Chronic Non-Cancer Pain Followed in Tertiary Care Settings
}

\author{
Jean-Luc Kaboré (D) ${ }^{1,2}$ \\ Manon Choinière $\mathbb{D}^{2,3}$ \\ Lise Dassieu (1D ${ }^{2}$ \\ Anaïs Lacasse $\mathbb{D}^{4}$ \\ M Gabrielle Pagé (D) ${ }^{2,3,5}$ \\ 'Department of Pharmacology and \\ Physiology, Faculty of Medicine, \\ Université de Montréal, Montreal, \\ Quebec, Canada; ${ }^{2}$ Research Centre of \\ the Centre Hospitalier de l'Université de \\ Montréal (CRCHUM), Montreal, \\ Quebec, Canada; ${ }^{3}$ Department of \\ Anesthesiology and Pain Medicine, \\ Faculty of Medicine, Université de \\ Montréal, Montreal, Quebec, Canada; \\ ${ }^{4}$ Department of Health Sciences, \\ Université du Québec en Abitibi- \\ Témiscamingue (UQAT), Rouyn- \\ Noranda, Quebec, Canada; ${ }^{5}$ Department \\ of Psychology, Faculty of Arts and \\ Science, Université de Montréal, \\ Montreal, Quebec, Canada
}

Correspondence: M Gabrielle Pagé Research Centre of the Centre Hospitalier de l'Université de Montréal, Montreal, Quebec, Canada

Tel + | 5|4-890-8000 ext. 3160|

$\mathrm{Fax}+\mid$ 5|4-4I2-7027

Email gabrielle.page@umontreal.ca
Background: Opioid doctor shopping has not yet been investigated in patients followed in tertiary care settings. This study aimed at assessing the prevalence of opioid doctor shopping among patients with chronic non-cancer pain (CNCP) (ie, pain lasting $\geq 3$ months) attending multidisciplinary pain clinics in Quebec, Canada.

Patients and Methods: This was a retrospective cohort study of patients with CNCP enrolled in the Quebec Pain Registry (QPR) between 2008 and 2014. QPR data were linked to the Quebec health insurance databases. The index date was the date of the first visit at the pain clinic. Prevalence of doctor shopping was assessed within the 12 months following the index date. Doctor shopping was defined as at least 1 day of overlapping opioid prescriptions from $\geq 2$ prescribers and filled in $\geq 3$ pharmacies.

Results: A total of 2191 patients with CNCP with at least one opioid dispensation within the 12 months following the index date were included. The mean age was $58.6 \pm 14.9$ years and $41.3 \%$ were men. The median pain duration was 4 years, and $13.3 \%$ of patients were diagnosed with neuropathic pain. Regarding past year comorbidities, $15.0 \%$ presented anxiety, $16.8 \%$ depression and $6.4 \%$ substance use disorder. Among the included patients, $15(0.7 \%)$ presented at least one episode of doctor shopping. Among these doctor-shoppers, 9 $(60.0 \%)$ exhibited only 1 episode.

Conclusion: Opioid doctor shopping is a rare phenomenon among patients with CNCP treated in tertiary care settings. Opioids should remain a drug option for patients without substance use disorder, and who have persistent pain despite optimized nonopioid therapy.

Keywords: opioids, doctor shopping, chronic non-cancer pain, Quebec Pain Registry

\section{Introduction}

The recent and ongoing opioid crisis in the United States (US) and Canada has led to increased opioid-related overdoses and has been declared a public health emergency. ${ }^{1}$ In the US, 47,600 drug overdose deaths involving an opioid occurred in 2018 alone. $^{2}$ In Canada, 16,364 opioid-related deaths occurred between January 2016 and March 2020. ${ }^{3}$ Most of these overdoses were driven primarily by illicitly manufactured fentanyl but prescription opioids were also responsible for some of these deaths. ${ }^{2,4}$ In the US, prescription opioids were reported in $32 \%$ of opioid-related deaths, ${ }^{2}$ while in Canada, $17 \%$ of opioid-related deaths involved only prescription opioids and $9 \%$ both prescription and illicit opioids. ${ }^{3}$ Public health measures such as prescription guidelines for prescribing opioids for chronic pain were issued to reduce problematic opioid use. ${ }^{5,6}$ Indeed, opioid use in CNCP was 
associated with a risk of developing opioid use disorders estimated at 5.5\% among those starting opioid therapy. ${ }^{6}$ One way to obtain opioids for problematic use is doctor shopping.

Doctor shopping can be defined as the behaviour of visiting different prescribers and/or pharmacies to obtain large amounts of opioids and suggests opioid use problems. $^{7-9}$ The prevalence of opioid doctor shopping is variable ranging from $0.2 \%$ to $4 \% .^{7,10-12}$ Studies also suggested that doctor shopping is associated with occurrence of opioid overdoses. ${ }^{13-16}$ However, doctor shopping has not yet been investigated in patients with chronic noncancer pain (CNCP) followed in tertiary care settings. Thus, the aim of this study was to assess the prevalence of opioid doctor shopping behaviours among patients with $\mathrm{CNCP}$ attending multidisciplinary pain treatment clinics.

\section{Patients and Methods Study Design}

This was a retrospective cohort study of patients with CNCP attending one of five multidisciplinary pain treatment clinics in Quebec, Canada, between 2008 and 2014.

\section{Data Sources}

Data were extracted from the Quebec Pain Registry (QPR) and linked to the Régie de l'assurance maladie du Québec (RAMQ) databases. Ethical approval for this study was obtained from the Research Ethics Board (REB) of the Centre hospitalier de l'Université de Montréal and from the Commission d'accès à l'information (CAI) of Quebec. The QPR is a registry of patients admitted to one of five multidisciplinary pain treatment clinics in the province of Quebec. ${ }^{17}$ Chronic pain was defined as pain lasting for at least 3 months. ${ }^{18}$ Patients aged 18 years and older, fluent in French and/or English, who were enrolled in the QPR between 2008 and 2014, and who provided written informed consent to use their QPR data for research purposes (92\%) were eligible for participation in the present study. QPR data included sociodemographic information and pain characteristics at the initial visit. The RAMQ databases contain information from reimbursed services dispensed to patients covered by the Quebec health insurance plan. The Quebec health insurance covered all Quebec residents for medical, hospital and emergency services and covers approximately $46 \%$ of Quebec residents for prescription drugs. The population who benefit from prescription drugs plan comprised persons aged 65 years and older, recipients of social assistance as well as the workers who were not covered by a private drug insurance plan. Drug dispensation for persons insured under a private plan is therefore not available in the RAMQ databases. Thus, only persons covered by the Quebec Public Drug Insurance plan were included in this study. RAMQ data comprised information on dispensed drugs, comorbidities (medical diagnoses using International Classification of Diseases (ICD)-9 and ICD-10 codes), emergency visits, and hospitalizations. QPR data were linked to RAMQ databases using the patient's last name, first name, sex, date of birth, and unique Quebec health insurance number. All data were de-identified at the times of the analyses.

\section{Participants}

QPR patients with a diagnosis of chronic non-cancer pain and at least one opioid dispensation within the 12 months following their first visit at the pain clinic were selected. Diagnosis of pain was established by the pain physician at the multidisciplinary pain clinic. Opioids included codeine, dextropropoxyphene, fentanyl, hydromorphone, meperidine, morphine, oxycodone, tapentadol, tramadol, butorphanol, and pentazocine.

\section{Measures}

Pain intensity was assessed using a standardized numerical pain ranging from 0 (no pain) to 10 (worst possible pain). Pain interference was measured using the interference items of the Brief Pain Inventory-10 with scores ranged from 0 (pain does not interfere) to 10 (pain interferes completely).

Neuropathic pain was defined as the presence of a physician diagnosis of neuropathic pain and score $\geq 4$ on the self-reported portion of Douleur Neuropathique 4 Questions (DN4); Mixed evidence of neuropathic was defined as the presence of a physician diagnosis of neuropathic pain and a DN4 score $<4$ or a diagnosis of nonneuropathic pain with a DN4 score $\geq 4$; Non-neuropathic pain was defined as the presence of a diagnosis of nonneuropathic pain with a DN4 score $<4$.

Past-year comorbidities were identified by the occurrence of at least one ICD-9 or ICD-10 code in the past 12 months preceding the index date. Past 3-month drug use was identified by at least one drug dispensation in the 3 months preceding the index date.

\section{Outcomes}

The outcome was the presence of opioid doctor shopping behaviours within the 12 months following the index date. 
Doctor shopping was defined as at least 1 day of overlapping prescriptions from $\geq 2$ prescribers and filled in $\geq 3$ pharmacies. $^{9,10}$ This definition of doctor shopping has been used in several studies, ${ }^{9-12}$ and has been shown to be associated with a clinical diagnosis of opioid use disorder. $^{9}$

\section{Statistical Analysis}

Descriptive statistical analysis was performed to estimate the prevalence of doctor shopping. Categorical variables are presented as frequency and percentage and quantitative variables as mean \pm standard deviation or median and interquartile range. Statistical analyses were performed using Stata/SE 16.1 for Windows (StataCorp LLC, College Station, TX, USA).

\section{Results}

A total of 7983 patients from the QPR had their data matched to the RAMQ databases. Among these patients, 4047 (50.7\%) were covered by the Quebec drug insurance plan, from 6-month before to 12-month period following their first visit at the pain clinic. Comparison between patients covered by the Quebec drug insurance plan and those not, revealed no difference for sex but showed difference for age (Mean age of $58.5 \pm 14.5$ years for patients covered by drug insurance plan versus $48.0 \pm 11.7$ years for those not covered), $\mathrm{p}<0.001$.

Among the 4047 patients covered by the Quebec drug insurance plan, a total of $2191 \mathrm{CNCP}$ patients with at least one opioid dispensation within the 12 months following the first visit at the pain clinic were included in the present study (Figure 1). The mean age was $58.6 \pm 14.9$ years and $41.3 \%$ were men. The median pain duration was 4 years $(\mathrm{Q} 1=1.5 ; \mathrm{Q} 3=10)$ and 291 patients $(13.3 \%)$ had neuropathic pain, $1270(58.0 \%)$ mixed evidence of neuropathic pain, and the remaining $630(28.8 \%)$ non-neuropathic pain. About past 12-month history of comorbidities, $6.4 \%$ presented a substance use disorder, $15.0 \%$ anxiety, and $16.8 \%$ depression (Table 1 ).

Only 15 out of the 2191 patients with CNCP (0.7\%) who received at least one opioid dispensation within the 12-month timeframe after the index date engaged in doctor shopping. People who exhibited doctor shopping were more likely to be younger and male and most of them presented mixed-evidence of neuropathic pain and past 3-month use of benzodiazepines (Table 1).

None of the patients who started opioid use after their first visit at the pain clinic (no opioid dispensation in the past 6-month before the index date; $\mathrm{n}=591$ ) had practiced doctor shopping. Among the 15 people identified as engaging in behaviours indicative of doctor shopping, 9 $(60.0 \%)$ had only 1 episode, 2 patients had two episodes, 2 patients had between 5-10 episodes, and 1 had 22 episodes. Patients who exhibited doctor shopping visited 2 to 26 different physicians for opioid prescriptions which were filled in 3 to 14 different pharmacies within the 12 months following their first visit at the pain clinic.

\section{Discussion}

This study which was the first to assess the prevalence of opioid doctor shopping in patients with $\mathrm{CNCP}$ attending multidisciplinary pain treatment clinics revealed that this type of behaviour is infrequent among these patients. Doctor shopping is viewed as a relevant indicator of inappropriate access to prescriptions and a proxy for nonmedical use. ${ }^{7-9}$ Some studies have shown that the use of multiple physicians and pharmacies to obtain opioid medications is associated with a clinical diagnosis of opioid use disorder and with opioid overdoses. ${ }^{9,16}$

Previous studies using the same definition of opioid doctor shopping as in this study reported a prevalence ranging from 0.2 to $0.8 \%$ in the US before the peak of the opioid overdose crisis. ${ }^{9,10}$ Studies from France focusing on patients with CNCP reported rates of opioid doctor shopping varying from 1 to $4 \% .^{11,12}$ These previous studies, based on data from medico-administrative databases, included all opioid users, not just those in tertiary care settings. This study was the first to focus exclusively on tertiary care patients and the findings revealed a lower rate of $0.7 \%$ which suggests that doctor shopping is a rare behaviour among patients with CNCP followed in tertiary care settings. The presence of a medical diagnosis of opioid use disorder in the 12 months preceding the first visit at the pain clinic was also low (6.4\%). This low prevalence of doctor shopping may be explained by the older age of patients followed in tertiary care settings since studies reported that doctor shopping was practiced mainly

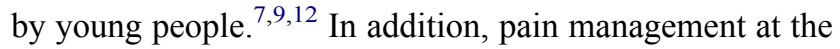
multidisciplinary pain treatment clinics was personalized according to the patients' needs and characteristics; ${ }^{17}$ thus, patients who received opioid prescriptions were probably those at lower risk of opioid use disorders. In the context of restrictions due to the opioid overdose crisis, this low rate of doctor shopping suggests that patients treated in multidisciplinary pain treatment clinics are rarely drug seekers and call for appropriate access to opioids which 


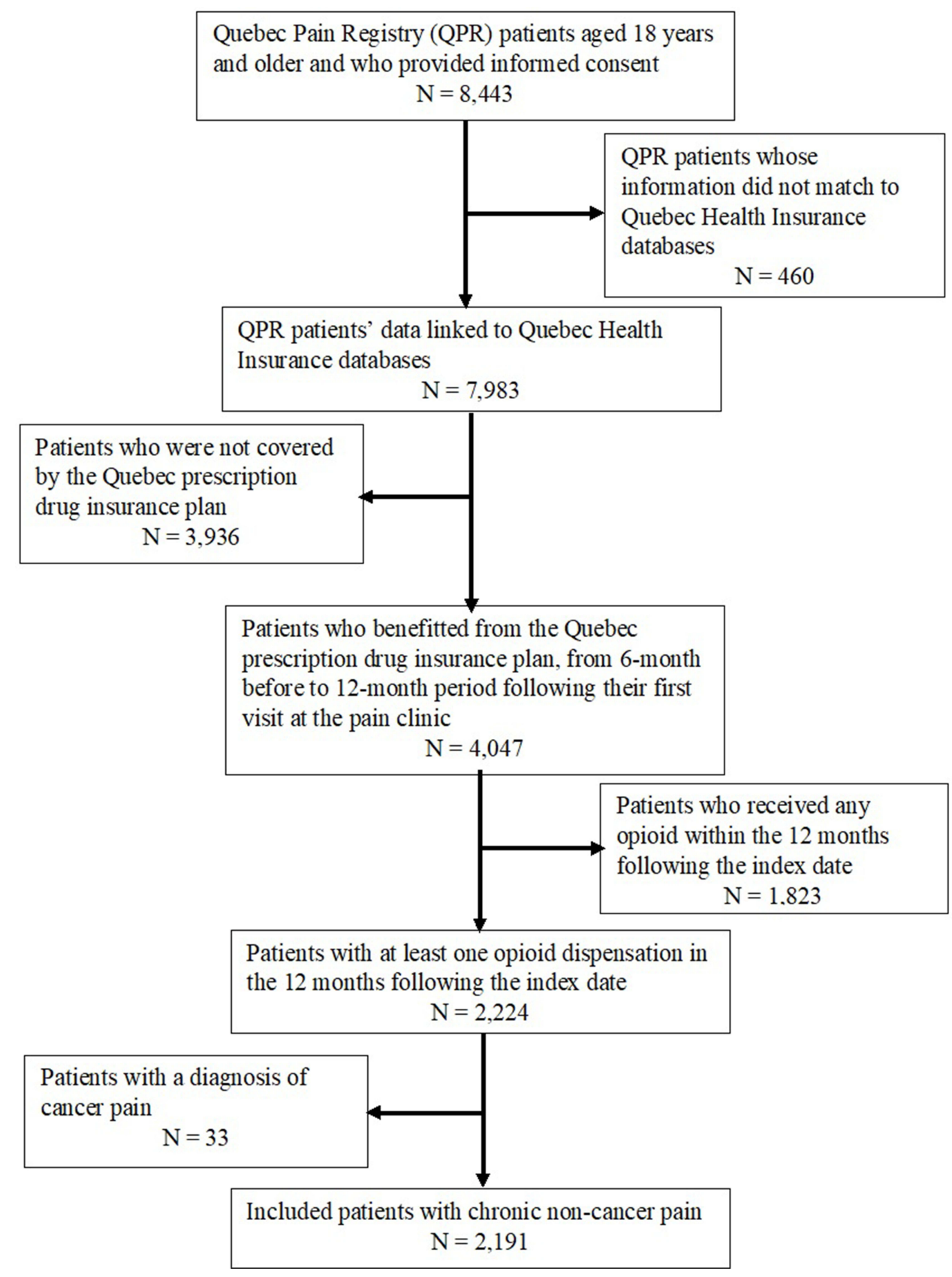

Figure I Flow chart of patients' inclusion (index date is the date of the first visit at the pain clinic).

remain useful medications for some patients. Furthermore, Quebec, like the other provinces in Canada, endorsed the Canadian Guideline for Safe and Effective Use of Opioids for Chronic Non-Cancer Pain Published in 2011 by the National Opioid Use Guideline Group (NOUGG), ${ }^{19}$ before endorsing the new guidelines issued in 2017 in the context of the opioid crisis. ${ }^{6}$ Although Quebec has adopted the same guidelines as other provinces in Canada, Quebec was the province where the opioid crisis was the least severe.
A report suggested that the prevalence of opioid use in Quebec remained low and stable from 2006 to 2016 while the indicators of potentially inappropriate opioid use such as prescription overlap were low and declining between 2006 and 2013. ${ }^{20}$ Thus, the low rate of doctor shopping reported in this study could result from the general context of Quebec where rates of opioid use as well as inappropriate use were low and declining. Nevertheless, adequate prescription monitoring and regular benefit-risk 
Table I Characteristics of Patients Included in the Analysis

\begin{tabular}{|c|c|c|c|}
\hline \multirow[t]{3}{*}{ Variables } & \multirow[t]{2}{*}{ All } & \multicolumn{2}{|c|}{ Doctor Shopping } \\
\hline & & No & Yes \\
\hline & n (\%) & n (\%) & n (\%) \\
\hline $\mathrm{N}$ & $2191(100.0)$ & $2176(99.3)$ & $15(0.7)$ \\
\hline \multicolumn{4}{|l|}{ Socio-demographics } \\
\hline $\begin{array}{l}\text { Age } \\
\text { - Mean } \pm S D\end{array}$ & $58.6 \pm 14.9$ & $58.7 \pm \mid 4.9$ & $46.1 \pm 7.5$ \\
\hline $\begin{array}{l}\text { Sex } \\
\text { - Male - N (\%) }\end{array}$ & $\begin{array}{c}N(\%) \\
905(4 I .3)\end{array}$ & $\begin{array}{c}n(\%) \\
897(4 \mid .2)\end{array}$ & $\begin{array}{c}\mathrm{n}(\%) \\
8(53.3)\end{array}$ \\
\hline $\begin{array}{l}\text { Education level completed } \\
\text { - College/University }\end{array}$ & $\begin{array}{c}N(\%) \\
934(42.6)\end{array}$ & $\begin{array}{c}n(\%) \\
927(44.6)\end{array}$ & $\begin{array}{c}n(\%) \\
7(46.7)\end{array}$ \\
\hline \multicolumn{4}{|l|}{ Pain characteristics } \\
\hline $\begin{array}{l}\text { Pain intensity in the past } 7 \text { days }^{\mathrm{a}} \\
\text { - Mean } \pm \mathrm{SD}\end{array}$ & $7.3 \pm 1.8$ & $7.3 \pm 1.8$ & $7.8 \pm 1.1$ \\
\hline $\begin{array}{l}\text { Pain interference in the past } 7 \text { days }^{\mathrm{b}} \\
\text { - Mean } \pm \mathrm{SD}\end{array}$ & $6.2 \pm 2.1$ & $6.2 \pm 2.1$ & $7.5 \pm 1.2$ \\
\hline $\begin{array}{l}\text { Pain duration (years) } \\
\text { - Median (QI - Q3) }\end{array}$ & $4(1.5-10)$ & $4(1.5-10)$ & $6(1.5-12)$ \\
\hline $\begin{array}{l}\text { Type of pain }{ }^{c} \\
\text { - Neuropathic } \\
\text { - Mixed evidence of neuropathic } \\
\text { - Non-neuropathic }\end{array}$ & $\begin{array}{c}N(\%) \\
291(13.3) \\
1270(58.0) \\
630(28.8)\end{array}$ & $\begin{array}{c}n(\%) \\
29 \mid(13.4) \\
1258(57.8) \\
627(28.8)\end{array}$ & $\begin{array}{c}n(\%) \\
0(0.0) \\
12(80.0) \\
3(20.0)\end{array}$ \\
\hline $\begin{array}{l}\text { Past-year comorbidities }^{\mathrm{d}} \\
\text { - Substance use disorders } \\
\text { - Depression } \\
\text { - Anxiety }\end{array}$ & $\begin{array}{c}N(\%) \\
140(6.4) \\
367(16.8) \\
328(15.0)\end{array}$ & $\begin{array}{c}n(\%) \\
137(6.3) \\
364(16.7) \\
322(14.8)\end{array}$ & $\begin{array}{c}n(\%) \\
3(20.0) \\
3(20.0) \\
6(40.0)\end{array}$ \\
\hline $\begin{array}{l}\text { Past 3-month drug use } \\
\text { - Benzodiazepines } \\
\text { - Antidepressants } \\
\text { - Antipsychotics } \\
\text { - Antiepileptics }\end{array}$ & $\begin{array}{c}N(\%) \\
908(41.4) \\
962(43.9) \\
258(11.8) \\
1191(54.4)\end{array}$ & $\begin{array}{c}\mathrm{n}(\%) \\
897(41.2) \\
958(44.0) \\
257(11.8) \\
1182(54.3)\end{array}$ & $\begin{array}{c}\mathrm{n}(\%) \\
\text { II (73.3) } \\
4(26.7) \\
\text { I (6.7) } \\
9(60.0)\end{array}$ \\
\hline
\end{tabular}

Notes: a Pain intensity was assessed using a standardized numerical pain ranging from 0 (no pain) to 10 (worst possible pain. ${ }^{b}$ Pain interference was measured using the interference items of the Brief Pain Inventory-10; scores ranged from 0 (pain does not interfere) to 10 (pain interferes completely). ${ }^{\mathrm{C}} \mathrm{Neuropathic}$ pain: physician diagnosis of neuropathic pain and score $\geq 4$ on the self-reported portion of Douleur Neuropathique 4 Questions (DN4)); Mixed evidence of neuropathic pain: physician diagnosis of neuropathic pain and a DN4 score $<4$ or a diagnosis of non-neuropathic pain with a DN4 score $\geq 4$; Non-neuropathic pain: a diagnosis of non-neuropathic pain with a DN4 score $<4$. ${ }^{d}$ Past-year comorbidities were identified by the occurrence of at least one ICD-9 or ICD-10 code in the past 12 months preceding the index date. ${ }^{e}$ Past 3 -month drug use was identified by at least one drug dispensation in the 3 months preceding the index date.

assessment of opioid therapy are needed for safe and effective opioid use.

This study presents limitations. First, doctor shopping can be practiced for reasons other than non-medical use such as for convenience, drug and prescriber availability, or insufficient pain relief. ${ }^{21}$ In addition, there are heterogeneous definitions of doctor shopping and therefore the prevalence could differ from one definition to another.
Furthermore, doctor shopping is not the sole way to obtain more opioids than prescribed; thus, clinicians should monitor potential sources of non-prescribed opioids. Second, data from health insurance databases do not indicate if supplemental drugs obtained through doctor shopping were used by the patients themselves or were diverted to somebody else. Another limitation is that only $50.7 \%$ of the selected QPR patients were covered 
by the Quebec drug insurance plan and these patients were older than those not covered by this insurance plan; Considering younger age was reported in several studies as a factor associated with doctor shopping, ${ }^{9-12}$ the prevalence reported in this study could be underestimated. Finally, the small sample size did not enable conducting supplementary analyses to better characterize doctorshoppers.

\section{Conclusions}

Opioid doctor shopping was practiced by less than $1 \%$ of patients with CNCP attending multidisciplinary pain clinics suggesting a low risk of non-medical use. Opioids remain useful medications that should be prescribed for patients with chronic noncancer pain, without current or past substance use disorder and without other active psychiatric disorders, who have persistent problematic pain despite optimized nonopioid therapy, as suggested by the Guidelines. ${ }^{6}$

\section{Author Contributions}

All authors made significant contribution to the work reported, have written or substantially and critically reviewed the article, have agreed to submit the article for publication to the Journal of Pain Research, reviewed and agreed on the final version of the article, and agree to take responsibility and be accountable for the contents of the article.

\section{Funding}

This study was funded by the Canadian Institutes of Health Research (\#PCG - 155472).

\section{Disclosure}

Prof. Dr. Manon Choinière reports personal fees from Michael G DeGroote Institute for Pain Research and Care, outside the submitted work. Dr Lise Dassieu reports grants from Canadian Institutes of Health Research, during the conduct of the study. Prof. Dr. Anais Lacasse is a Junior 2 research scholar from the Fonds de recherche du Québec Santé (FRQS). The Chronic Pain Epidemiology Laboratory led by A Lacasse is funded by the Fondation de l'Universite du Québec en Abitibi-Témiscamingue (UQAT), in partnership with local businesses: the Pharmacie Jean-Coutu de Rouyn-Noranda (community pharmacy) and Glencore Fonderie Horne (copper smelter). Prof. Dr. M Gabrielle Pagé reports personal fees from Canopy Growth, outside the submitted work. The authors declare that they have no other competing interests.

\section{References}

1. Ayoo K, Mikhaeil J, Huang A, Wąsowicz M. The opioid crisis in North America: facts and future lessons for Europe. Anaesthesiol Intensive Ther. 2020;52(2):139-147. doi:10.5114/ait.2020.94756

2. Wilson N, Kariisa M, Seth P, Smith H, Davis NL. Drug and opioidinvolved overdose deaths - United States, 2017-2018. MMWR Morb Mortal Wkly Rep. 2020;69(11):290-297. doi:10.15585/mmwr. mm6911a4

3. Special Advisory Committee on the Epidemic of Opioid Overdoses. Opioid-related harms in Canada. Ottawa: Public Health Agency of Canada; 2020. Available from: https://health-infobase.canada.ca/sub stance-related-harms/opioids/. Accessed December 15, 2020.

4. Crabtree A, Lostchuck E, Chong M, Shapiro A, Slaunwhite A. Toxicology and prescribed medication histories among people experiencing fatal illicit drug overdose in British Columbia, Canada. CMAJ. 2020;192(34):E967-E972. doi:10.1503/cmaj.200191

5. Dowell D, Haegerich TM, Chou R. CDC guideline for prescribing opioids for chronic pain-United States, 2016. JAMA. 2016;315 (15):1624-1645. doi:10.1001/jama.2016.1464

6. Busse JW, Craigie S, Juurlink DN, et al. Guideline for opioid therapy and chronic noncancer pain. CMAJ. 2017;189(18):E659-E666. doi:10.1503/cmaj. 170363

7. Biernikiewicz M, Taieb V, Toumi M. Characteristics of doctor-shoppers: a systematic literature review. J Mark Access Health Policy. 2019;7(1):1595953. doi:10.1080/ 20016689.2019.1595953

8. Esposito DB, Cepeda MS, Lyons JG, Yin R, Lanes S; Group O behalf of TM of the OP-MCOSW. Medical record-based ascertainment of behaviors suggestive of opioid misuse, diversion, abuse, and/or addiction among individuals showing evidence of doctor/pharmacy shopping. J Pain Res. 2019;12:2291. doi:10.2147/JPR.S203350

9. Cepeda MS, Fife D, Kihm MA, Mastrogiovanni G, Yuan Y. Comparison of the risks of shopping behavior and opioid abuse between tapentadol and oxycodone and association of shopping behavior and opioid abuse. Clin J Pain. 2014;30(12):1051-1056. doi:10.1097/AJP.0000000000000067

10. Cepeda MS, Fife D, Vo L, Mastrogiovanni G, Yuan Y. Comparison of opioid doctor shopping for tapentadol and oxycodone: a cohort study. J Pain. 2013;14(2):158-164. doi:10.1016/j.jpain.2012.10.012

11. Chenaf C, Kabore J-L, Delorme J, et al. Incidence of tramadol shopping behavior in a retrospective cohort of chronic non-cancer pain patients in France. Pharmacoepidemiol Drug Saf. 2016;25 (9):1088-1098. doi:10.1002/pds.4056

12. Chenaf C, Kabore J-L, Delorme J, et al. Codeine shopping behavior in a retrospective cohort of chronic noncancer pain patients: incidence and risk factors. J Pain. 2016;17(12):1291-1301. doi:10.1016/ j.jpain.2016.08.010

13. Peirce GL, Smith MJ, Abate MA, Halverson J. Doctor and pharmacy shopping for controlled substances. Med Care. 2012;50(6):494-500. doi:10.1097/MLR.0b013e31824ebd81

14. Hall AJ, Logan JE, Toblin RL, et al. Patterns of abuse among unintentional pharmaceutical overdose fatalities. JAMA. 2008;300 (22):2613-2620. doi:10.1001/jama.2008.802

15. Gwira Baumblatt JA, Wiedeman C, Dunn JR, Schaffner W, Paulozzi LJ, Jones TF. High-risk use by patients prescribed opioids for pain and its role in overdose deaths. JAMA Intern Med. 2014;174 (5):796-801. doi:10.1001/jamainternmed.2013.12711

16. Yang Z, Wilsey B, Bohm M, et al. Defining risk for prescription opioid overdose: pharmacy shopping and overlapping prescriptions among long-term opioid users in Medicaid. J Pain. 2015;16 (5):445-453. doi:10.1016/j.jpain.2015.01.475 
17. Choinière M, Ware MA, Pagé MG, et al. Development and implementation of a registry of patients attending multidisciplinary pain treatment clinics: the Quebec Pain Registry. Pain Res Manag. 2017;2017:e8123812. doi:10.1155/2017/8123812

18. Treede R-D, Rief W, Barke A, et al. A classification of chronic pain for ICD-11. Pain. 2015;156(6):1003-1007. doi:10.1097/j. pain.0000000000000160

19. Kahan M, Mailis-Gagnon A, Wilson L, Srivastava A. Canadian guideline for safe and effective use of opioids for chronic noncancer pain clinical summary for family physicians. Part 1: general population. Can Fam Physician. 2011;57(11):1257-1266.
20. Daigle J-M, Tremblay É, Beaulieu C, Breton M-C, Bouchard S; Institut national d'excellence en santé et en services sociaux (Québec). Portrait of opioid use in persons covered by Quebec's public prescription drug insurance; 2018. Available from: https://www.inesss. qc.ca/fileadmin/doc/INESSS/Rapports/Medicaments/INESSS Portrait_Opio\%C3\%AFdes.pdf. Accessed September 20, 2020.

21. Stephenson JJ, Cepeda MS, Zhang J, et al. The association between doctor and pharmacy shopping and self-reported misuse and abuse of prescription opioids: a survey study. J Pain Res. 2020;13:689-701. doi:10.2147/JPR.S232409

\section{Publish your work in this journal}

The Journal of Pain Research is an international, peer reviewed, open access, online journal that welcomes laboratory and clinical findings in the fields of pain research and the prevention and management of pain. Original research, reviews, symposium reports, hypothesis formation and commentaries are all considered for publication. The manuscript

Submit your manuscript here: https://www.dovepress.com/journal-of-pain-research-journa management system is completely online and includes a very quick and fair peer-review system, which is all easy to use. Visit http:// www.dovepress.com/testimonials.php to read real quotes from published authors. 